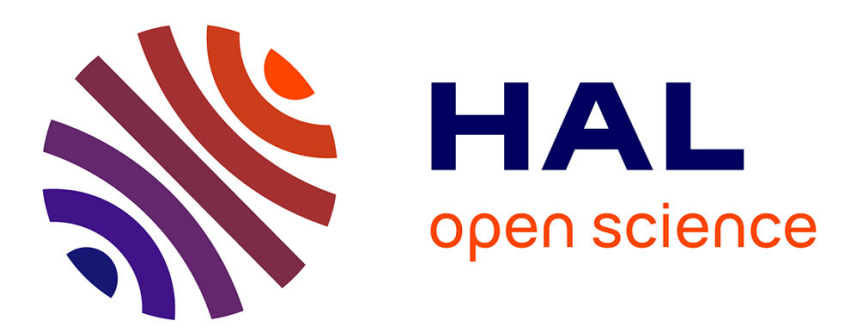

\title{
Maximum Torque Per Ampere Control Strategy of a 5-phase PM Generator in healthy and faulty modes for tidal marine turbine application
}

Ousmane Fall, Jean-Frederic Charpentier, Ngac-Ky Nguyen, Paul Letellier

\section{- To cite this version:}

Ousmane Fall, Jean-Frederic Charpentier, Ngac-Ky Nguyen, Paul Letellier. Maximum Torque Per Ampere Control Strategy of a 5-phase PM Generator in healthy and faulty modes for tidal marine turbine application. Power Electronics Conference (2014; Shanghai), Nov 2014, Shanghai, China. 6 p. hal-01086994

\section{HAL Id: hal-01086994 https://hal.science/hal-01086994}

Submitted on 25 Nov 2014

HAL is a multi-disciplinary open access archive for the deposit and dissemination of scientific research documents, whether they are published or not. The documents may come from teaching and research institutions in France or abroad, or from public or private research centers.
L'archive ouverte pluridisciplinaire HAL, est destinée au dépôt et à la diffusion de documents scientifiques de niveau recherche, publiés ou non, émanant des établissements d'enseignement et de recherche français ou étrangers, des laboratoires publics ou privés. 


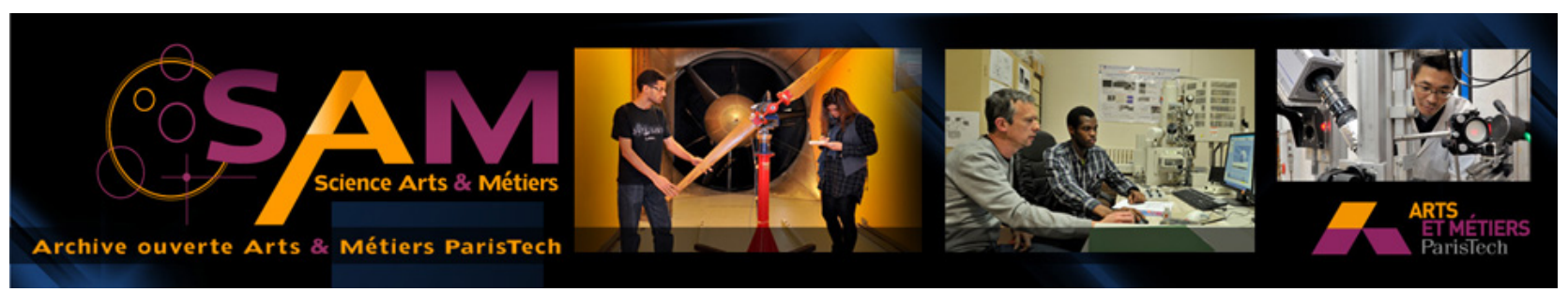

\section{Science Arts \& Métiers (SAM)}

is an open access repository that collects the work of Arts et Métiers ParisTech researchers and makes it freely available over the web where possible.

This is an author-deposited version published in: http://sam.ensam.eu

Handle ID: .http://hdl.handle.net/10985/8979

\section{To cite this version :}

Ousmane FALL, Jean-Frederic CHARPENTIER, Ngac-Ky NGUYEN, Paul LETELLIER -

Maximum Torque Per Ampere Control Strategy of a 5-phase PM Generator in healthy and faulty modes for tidal marine turbine application - In: Power Electronics Conference (2014; Shanghai), China, 2014-11 - Power Electronics Conference (IPEC-Hiroshima 2014 - ECCE-ASIA) - 2014 


\title{
Maximum Torque Per Ampere Control Strategy of a 5-phase PM Generator in healthy and faulty modes for tidal marine turbine application
}

\author{
Ousmane FALL ${ }^{(1,2,3)}$, Jean Frédéric CHARPENTIER ${ }^{(2)}$, Ngac-Ky NGUYEN ${ }^{(3)}$ Paul LETELLIER $^{(1)}$ \\ (1) Jeumont-Electric, 367 Rue de l'Industrie, 59460 Jeumont, France \\ (2) Ecole navale et groupe des écoles du Poulmic CC-600 29240 Brest, France \\ (3)Arts et Métiers Paristech-L2EP 8 Bd Louis XIV 59046 Lille, France \\ Ousmane.fall@ecole-navale.fr
}

\begin{abstract}
The work presented in this paper aims to propose a control strategy being able to extract efficiently energy from a fixed-pitch marine current turbine associated with a 5-phase Permanent Magnet Synchronous Generator (PMSG) in healthy mode and in faulty mode. The considered faults are opened phases. For each tidal current speed, the control strategy aims to extract the maximum power with respect of the maximum values of currents and voltages related to the converter. The maximum power is directly related to the Maximum Torque per Ampere (MTPA) control strategy characteristics (all the points which are below the MTPA torque VS rotating speed characteristic can be reached by the converter/generator set). This paper proposes a me thodology to establish MTPA characteristics and calculate the corresponding current references in healthy mode and in faulty mode (one or two opened phases) for a 5 -phase generator. The studied strategy includes flux weakening operations in the both modes.
\end{abstract}

Keywords - multiphase drive, marine energy, control strategy, healthy mode, fault mode, MTPA, flux weakening,

\section{INTRODUCTION}

Marine tidal current is considered to be an attractive solution to provide a clean renewable energy for coastal area because the tides which are related to astronomical phenomena are in first order predictable. Furthermore, this energy is characterized by a higher density than wind energy $[1,2]$. High potential tidal current spots have been identified in the previous years where currents exceed $2 \mathrm{~m} / \mathrm{s}$. As an example several high potential sites have been identified in the western coast of France and England [1,2].

In the past few years several technical options have been proposed in several projects for the tidal turbine system and a reference solution has not already been found [1].

Associating a PMSG with a back to back PWM IGBT converter and a Fixed-Pitch Turbine (FPT) could be really attractive solution because it leads to minimize the mechanical defaults. This kind of system offers a low level of maintenance operations (there is no need to maintain the gearbox and the pitch system). This point is fundamental in marine turbine context where the system is obviously very difficult to access.
However an elimination of the pitch system leads to a control of the marine turbine speed via only the power electronic converter. This is why a flux weakening control strategy is proposed in [3] for a 3-phase PMSG associated with a FPT to follow a power limitation strategy (the power is limited for high current speeds by flux weakening operations). This strategy allows finding a good compromise between the cost of the system which is related to electric parts sizing and the total amount of extracted energy. In effect, by considering the resource statistics, the period where the energy is high (corresponding to a high speed of the tidal current) during a year is very short.

Fault tolerant systems are also very attractive in the tidal current energy context. Fault tolerant systems allow to continue to extract energy even if a fault occurs. A fault tolerant system can be achieved by using additional components or by using multi-phase drives which have more degree of freedoms compared with traditional three-phase drives. This is why multiphase machines have been studied extensively in the past decade[4, 5, 6, 7]. This study deals with 5-phase machines and drives which offer possibility of working in fault mode (1 or 2 opened phases).

In order to assess the capability of such a system to be used for tidal turbine application, a global strategy to determine the MTPA control strategy is proposed in healthy mode and faulty modes. Results are presented for a laboratory scale low power PMSG.

\section{Multi MACHINE FORMALISM}

For modeling the 5-phase permanent magnet synchronous machine (PMSM), the following hypotheses are used:

- The 5 phases are regularly shifted.

- The saturation of the magnetic materials is not taken into account.

- Windings are wye connected.

The model of a 5-phase PMSM written in stator frame (the natural frame whose indices are $\mathrm{a}, \mathrm{b}, \mathrm{c}, \mathrm{d}$, e corresponding to

This work was funded by Jeumont-Electric Company 
each phase) does not allow an easy control of the drive due to the magnetic couplings between the phase windings.

To get a simplier control of the drive, a new modeling in the rotor frame is considered. This new frame is obtained by applying a generalized Concordia (equations (1) and (2)) and Park transformation (equation (3)). These transformations are fully described in [10] and presented below. Firstly electrical variables are expressed in a new Concordia frame as shown in equation (1).

$$
\left[\begin{array}{c}
x_{a} \\
x_{b} \\
x_{c} \\
x_{d} \\
x_{e}
\end{array}\right]=[T]\left[\begin{array}{c}
x_{0} \\
x_{\alpha 1} \\
x_{\beta 1} \\
x_{\alpha 3} \\
x_{\beta 3}
\end{array}\right] \Rightarrow\left[\begin{array}{c}
x_{0} \\
x_{\alpha 1} \\
x_{\beta 1} \\
x_{\alpha 3} \\
x_{\beta 3}
\end{array}\right]=[T]^{-1}\left[\begin{array}{c}
x_{a} \\
x_{b} \\
x_{c} \\
x_{d} \\
x_{e}
\end{array}\right]
$$

where:

$$
[T]=\left[\begin{array}{ccccc}
\frac{1}{\sqrt{2}} & \frac{1}{\sqrt{2}} & \frac{1}{\sqrt{2}} & \frac{1}{\sqrt{2}} & \frac{1}{\sqrt{2}} \\
1 & \cos \frac{2 \pi}{5} & \cos \frac{4 \pi}{5} & \cos \frac{6 \pi}{5} & \cos \frac{8 \pi}{5} \\
0 & \sin \frac{2 \pi}{5} & \sin \frac{4 \pi}{5} & \sin \frac{6 \pi}{5} & \sin \frac{8 \pi}{5} \\
1 & \cos \frac{4 \pi}{5} & \cos \frac{8 \pi}{5} & \cos \frac{12 \pi}{5} & \cos \frac{16 \pi}{5} \\
0 & \sin \frac{4 \pi}{5} & \sin \frac{8 \pi}{5} & \sin \frac{12 \pi}{5} & \sin \frac{16 \pi}{5}
\end{array}\right]
$$

After applying this generalized Concordia transform, a generalized Park transform (equation 3 ) allows to express the electrical variables in $2 \mathrm{~d}$-q rotating frames $\left(\mathrm{d}_{1} \mathrm{q}_{1}\right.$ and $\left.\mathrm{d}_{3} \mathrm{q}_{3}\right)$ and a zero-sequence component $\left(x_{0}\right)$.

$$
\left[\begin{array}{c}
x_{0} \\
x_{\alpha 1} \\
x_{\beta 1} \\
x_{\alpha 3} \\
x_{\beta 3}
\end{array}\right]=[R(\theta)]\left[\begin{array}{c}
x_{0} \\
x_{d 1} \\
x_{q 1} \\
x_{d 3} \\
x_{q 3}
\end{array}\right] \Rightarrow\left[\begin{array}{c}
x_{0} \\
x_{d 1} \\
x_{q 1} \\
x_{d 3} \\
x_{q 3}
\end{array}\right]=[R(\theta)]^{-1}\left[\begin{array}{c}
x_{0} \\
x_{\alpha 1} \\
x_{\beta 1} \\
x_{\alpha 3} \\
x_{\beta 3}
\end{array}\right]
$$

where:

$$
[R(\theta)]=\left[\begin{array}{ccccc}
1 & 0 & 0 & 0 & 0 \\
0 & \cos (\theta) & -\sin (\theta) & 0 & 0 \\
0 & \sin (\theta) & \cos (\theta) & 0 & 0 \\
0 & 0 & 0 & \cos (3 \theta) & \sin (3 \theta) \\
0 & 0 & 0 & -\sin (3 \theta) & \cos (3 \theta)
\end{array}\right]
$$

Indeed these new frames use eigenvectors of the inductance matrix. This leads to identify three specific subsystems corresponding to each eigenvalues of the inductance matrix. Two of these subsystems are two-dimensional and the third one has one dimension. This formalism allows us to consider the machine as two equivalent $\mathrm{d}-\mathrm{q}$ machines (primary and secondary) and a zero-sequence machine. These three machines are magnetically decoupled and mechanically coupled to the same shaft [8]. Each of these sub frames $\left(d_{1} q_{1}\right.$, $\mathrm{d}_{3} \mathrm{q}_{3}$ and ${ }_{0}$ ) is characterized by a cyclic inductance: $\mathrm{L}_{1 \mathrm{~d}}=\mathrm{L}_{1 \mathrm{q}}$, $\mathrm{L}_{3 \mathrm{~d}}=\mathrm{L}_{3 \mathrm{q}}$ and $\mathrm{L}_{0}$. The electrical variables (currents, voltages, fluxes, back-EMF, etc.) in the new sub frames are obtained by projecting the corresponding vectors into each subsystem. It is then possible to show that the zero-sequence sub system is only affected by multiple harmonics of five, the primary $\mathrm{d}-\mathrm{q}$ machine $\left(d_{1} q_{1}\right)$ is mainly affected by the fundamental and the secondary $d-q$ machine $\left(\mathrm{d}_{3} \mathrm{q}_{3}\right)$, is mainly affected by third harmonic[9],[10]. In the case where the phases are wye connected (as in this paper), the zero-sequence machine is not supplied.

In this new frame, the electrical voltage equations can be rewritten as [9][10]:

$$
\begin{aligned}
& v_{d 1}=R i_{d 1}+L_{d 1} \frac{d i_{d 1}}{d t}-p \Omega L_{q 1} i_{q 1} \\
& v_{q 1}=R i_{q 1}+L_{q 1} \frac{d i_{q 1}}{d t}+p \Omega\left(L_{d 1} i_{d 1}+\sqrt{\frac{5}{2}} \Phi_{1}\right) \\
& v_{d 3}=R i_{d 3}+L_{d 3} \frac{d i_{d 3}}{d t}+3 p \Omega L_{q 3} i_{q 3} \\
& v_{q 3}=R i_{q 3}+L_{q 3} \frac{d i_{q 3}}{d t}+3 p \Omega\left(L_{d 3} i_{d 3}+\sqrt{\frac{5}{2}} \Phi_{3}\right)
\end{aligned}
$$

where $\left(v_{d 1}, v_{q 1}, i_{d 1}, i_{q 1}\right)$ and $\left(v_{d 3}, v_{q 3}, i_{d 3}, i_{q 3}\right)$ corresponds to the projection of the phase voltages and the phase currents into the two independent $d-q$ frames respectively noted $\left(d_{1} q_{1}\right)$ (equation (1) and (2)) and $\left(\mathrm{d}_{3} \mathrm{q}_{3}\right)$ (equations (3) and (4)). As said previously the first harmonics of current, voltage, and EMF are projected in $\left(\mathrm{d}_{1} \mathrm{q}_{1}\right)$ frame and the third harmonics in $\left(\mathrm{d}_{3} \mathrm{q}_{3}\right)$ frame. $R$ is the phase resistance. $L_{1 d}, L_{1 q}$ and $L_{3 d}, L_{3 q}$ are the machine inductances corresponding to the two d-q axes of the two frames. With the hypotheses of non-saliency, $L_{1 q}=L_{1 d}$ and $L_{3 d}=L_{3 q}$.

Considering this representation the electromagnetic torque of the machine can be determined as:

$$
C=C_{1}+C_{3}
$$

with:

$$
\begin{aligned}
& C_{1}=p\left(\left(L_{d 1}-L_{q 1}\right) i_{d 1} i_{q 1}+\sqrt{\frac{5}{2}} \Phi_{1} i_{q 1}\right) \\
& C_{3}=p\left(3\left(L_{d 3}-L_{q 3}\right) i_{d 3} i_{q 3}+3 \sqrt{\frac{5}{2}} \Phi_{3} i_{q 3}\right)
\end{aligned}
$$

where $C_{1}$ is the torque created by the $\left(d_{1}-q_{1}\right)$ machine and $C_{3}$ is the torque created by the $\left(d_{3}-q_{3}\right)$ machine.

\section{MTPA CONTROL STRATEGY IN HEALTHY MODE}

A direct driven 5-phase PMSG associated with a fixed pitch turbine is considered in this study. This system is associated 
with a 5-phase IGBT back to back converter as shown in Figure 1. For a given site, the tidal speed varies continuously. As the result, the speed of the turbine and generator set must be adapted to each value of the tidal current to extract the maximum possible power according to a Maximum power point tracking (MPPT) strategy with power limitation. When high values of tidal speed are reached, a power limitation strategy is used. In the presented work, this power limitation is based on the flux weakening operation of a generator as described in [3]. So this strategy implies requirements on the MTPA torque/speed characteristic of the converter/machine set. This is why this paper focuses on the determination of this characteristic in healthy and fault mode. In healthy mode, the MTPA characteristics and control strategy of the converter / machine set is determined by a similar method presented than those presented in [11]. This method allows the calculation of the torque / speed characteristic and current references to reach the maximum possible torque for each value of speed considering that the phase currents and voltages must be limited to their maximum values (related to the rated current of the drive and the converter DC bus voltage level) [3][11][12].

In healthy mode, the voltages and currents are balanced, so only one phase ("phase a") needs to be considered. Maximum current and maximum voltage constraints can be expressed by equations (12) and (13). This inequality expresses that their values must be lower than the maximum values related to the limits of the converter and machine.

$$
\begin{aligned}
& i_{a}=I_{d 1} \cos (p \Omega t)-I_{q 1} \sin (p \Omega t)+I_{d 3} \cos (3 p \Omega t)-I_{q 3} \sin (3 p \Omega t) \leq I_{\text {max }} \\
& v_{a}=V_{d 1} \cos (p \Omega t)-V_{q 1} \sin (p \Omega t)+V_{d 3} \cos (3 p \Omega t)-V_{q 3} \sin (3 p \Omega t) \leq V_{\text {max }}
\end{aligned}
$$

where $p$ is the number of pole pairs of the machine, $\Omega$ is the rotational speed of the rotor; $I_{\max }$ and $V_{\max }$ are the limitations related to the current and voltage of the converter / machine set.

The determination of the MTPA characteristics can be seen as a nonlinear optimization problem, which aims to maximize torque (formula (9)) under constraints of current and voltage of the converter / machine set (equations (12) and (13)). The optimization variables are: $\mathrm{I}_{\mathrm{d} 1}, \mathrm{I}_{\mathrm{q} 1}, \mathrm{I}_{\mathrm{d} 3}$ and $\mathrm{I}_{\mathrm{q} 3}$. This allows us to determine, for each value of rotating speed, the optimal quadruplet of current references and the corresponding value of the torque.

The results of this optimization process are given in Figures 2,3 and 4 for a given generator / converter set. This generator / converter set corresponds to a low scale laboratory system. The main electrical parameters are given in Table I. In Figure 2, the results are obtained in case where the back-EMF of the generator contains $10 \%$ of the third harmonic. In Figure 3 and Figure 4, the back-EMF is supposed sinusoidal. As a consequence as shown In the case of figure 4, the machine is supplied by sinusoidal currents. It can be noticed that for this last case , the optimization variables are only $\mathrm{I}_{\mathrm{d} 1}$ and $\mathrm{I}_{\mathrm{q} 1}$ while $\left(\mathrm{I}_{\mathrm{d} 3}, \mathrm{I}_{\mathrm{q} 3}\right)$ are maintained to $(0,0)$.

Considering the obtained simulation results, two regions can be observed. The $1^{\text {st }}$ region, called the "constant torque" operation, corresponds to a low speed optimal MTPA control where the torque is maximum and constant. The $2^{\text {nd }}$ one, called the "flux weakening" operation, is started when the rotor speed exceeds the base speed. In this region the machine is operated in flux weakening mode by a current injection in the two direct-axis $\left(\mathrm{I}_{\mathrm{d} 1}\right.$ and $\left.\mathrm{I}_{\mathrm{d} 3}\right)$ of the two subsystems., the voltage and current are equal to their maximum values. The values of $\left(\mathrm{I}_{\mathrm{q} 1}\right.$, $\mathrm{I}_{\mathrm{q} 3}$ ) which are directly related to the electromagnetic torque (equation 9, 10 and 11) are then reduced to respect the constraint on maximum phase current (equation 12).

Undoubtedly, the currents $\mathrm{I}_{\mathrm{d} 1}, \mathrm{I}_{\mathrm{q} 1}, \mathrm{I}_{\mathrm{d} 3}$ and $\mathrm{I}_{\mathrm{q} 3}$ will depend strongly on the shape of the generator back-EMF. If the machine back-EMF contains a non-negligible level of the $3^{\text {rd }}$ harmonic as considered in Figure 2, the secondary d-q system $\left(d_{3} q_{3}\right)$ will contribute significantly to the average torque. Indeed the torque is then produced both by the primary and secondary sub-systems by simultaneous injection of the first and the third harmonics of currents. This allows an optimal low-speed torque of $46 \mathrm{Nm}$. The results obtained in Figure 4 consider only the first d-q system (there is no injection of the third harmonic of current) and a sinusoidal back-EMF. In this case, we obtain a maximum torque $(37 \mathrm{Nm})$ which is lower than the one of the previous case $(46 \mathrm{Nm})$. However, for a machine with a sinusoidal back-EMF, injecting a $3^{\text {rd }}$ harmonic of current (in an optimal way) can reduce the current magnitude. As a consequence, the first harmonic of current could be increased (up to 15\%) and allows to provide more torque. The simulation results for this strategy are shown in Figure 3 (maximum torque $=42 \mathrm{~N} . \mathrm{m}$ ).

These first results show that the MTPA characteristics in healthy mode are strongly linked to the design parameters of the machine (shape of the magnet, windings topology, etc.). Indeed, these parameters influence strongly the back-EMF waveform and the values of the inductances associated with the two d-q systems.

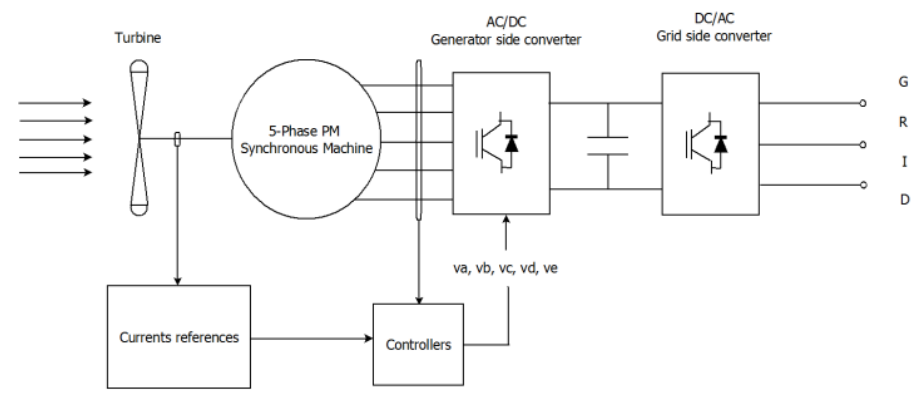

Fig. 1. General scheme of the tidal system.

TABLE I. ELECTRICALS PARAMETERS OF THE CONVERTERMACHINE SET

\begin{tabular}{|l|l|}
\hline \multicolumn{1}{|c|}{ Electrical parameter } & \multicolumn{1}{c|}{ Value } \\
\hline $\mathrm{L}_{\mathrm{ld}}=\mathrm{L}_{\mathrm{lq}}$ & $1.35 \mathrm{mH}$ \\
\hline $\mathrm{L}_{3 \mathrm{~d}}=\mathrm{L}_{3 \mathrm{q}}$ & $0.51 \mathrm{mH}$ \\
\hline Magnet flux (1 ${ }^{\text {st }}$ harmonics) $\Phi_{1}$ & $59.97 \mathrm{mWb}$ \\
\hline Number of pole pairs & $\mathrm{p}=10$ \\
\hline DC bus voltage & $\mathrm{V}_{\mathrm{dc}}=120 \mathrm{~V}$ \\
\hline Maximum current & $\mathrm{I}_{\max }=25 \mathrm{~A}$ \\
\hline
\end{tabular}



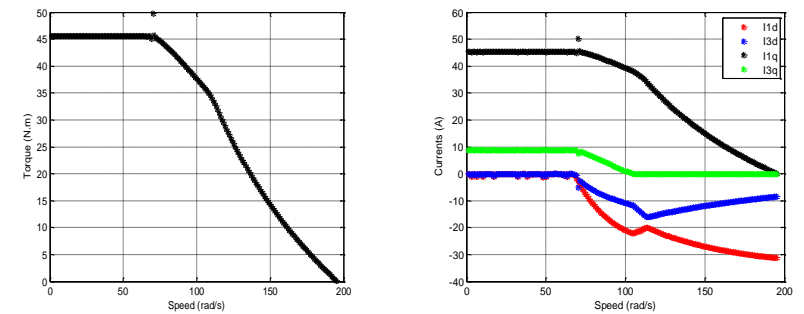

Fig. 2. Torque and current waveforms for the case where the back-EMF contains a significative part of $3^{\text {rd }}$ harmonic $(\Phi 3=10 \% \Phi 1)$ with optimal injection of $3^{\text {rd }}$ harmonic of current.
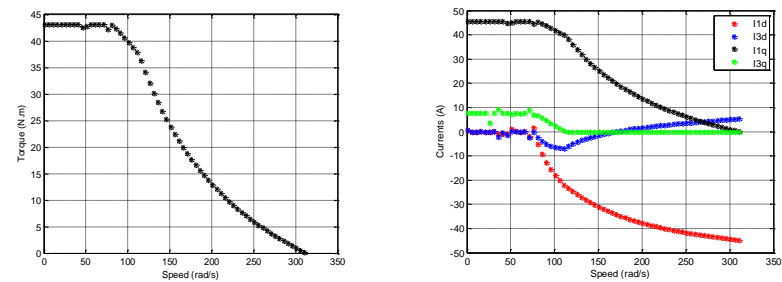

Fig. 3. Torque and current waveforms for a machine having a purely sinusoidal back-EMF, with optimal injection of $3^{\text {rd }}$ harmonic of current.
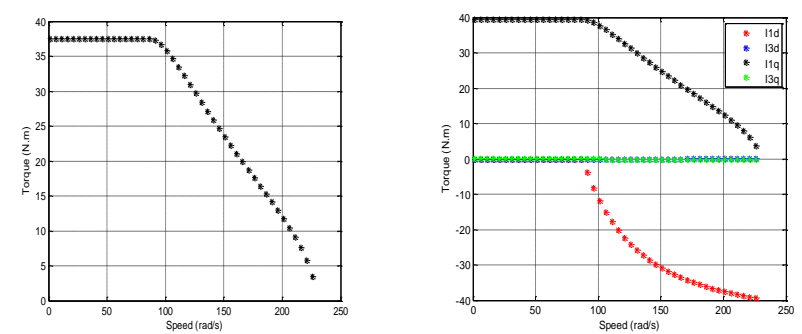

Fig. 4. Torque and current waveforms for a machine with purely sinusoidal EMF, without injection of 3rd harmonic of current (sinusoidal current)

\section{DETERMINATION OF MTPA CONTROL STRATEGY IN FAULTY MODE}

Although the machine is mainly designed to operate in healthy mode, it is important to evaluate the capabilities of the drive to operate in faulted mode because of the difficulties to perform maintenance on tidal sites. It is desirable that the machine must be able to work in faulted mode with satisfied performances. Among the most frequent problems, the presented work focus in faults related to the converter and particularly on open phase faults [10]. It is assumed in this part that the back-EMF of the generator is purely sinusoidal. In this studied case, the machine is initially supplied with a balanced system of sinusoidal currents as considered in [5, 6]:

$$
\left[\begin{array}{c}
i_{a} \\
i_{b} \\
i_{c} \\
i_{d} \\
i_{e}
\end{array}\right]=I_{\max }\left[\begin{array}{c}
\cos (\omega t+\psi) \\
\cos (\omega t-2 \pi / 5+\psi) \\
\cos (\omega t-4 \pi / 5+\psi) \\
\cos (\omega t-6 \pi / 5+\psi) \\
\cos (\omega t-8 \pi / 5+\psi)
\end{array}\right]
$$

With $\omega t=\theta_{\text {elec }}, \omega$ is the electrical pulsation and $\theta_{\text {elec }}$ is the rotor position in electrical angle. $\psi$ is the phase shift between the currents and the back-EMF. Applying the Concordia transformation to (14) lead to:

$$
\left\{\begin{array}{l}
\frac{5}{2} I_{\max } \cos (\omega t+\psi)=i_{a}+\cos \left(\frac{2 \pi}{5}\right)\left(i_{b}+i_{e}\right)+\cos \left(\frac{4 \pi}{5}\right)\left(i_{c}+i_{d}\right) \\
\frac{5}{2} I_{\max } \sin (\omega t+\psi)=\sin \left(\frac{2 \pi}{5}\right)\left(i_{b}-i_{e}\right)+\sin \left(\frac{4 \pi}{5}\right)\left(i_{c}-i_{d}\right)
\end{array}\right.
$$

It can be noticed that if the multi-machine formalism is used, these two components correspond to the currents in the primary subsystem $\left(\alpha_{1}, \beta_{1}\right)$. This corresponds to the constant currents in the Park reference frame, i.e. $\mathrm{I}_{\mathrm{d} 1}$ and $\mathrm{I}_{\mathrm{q} 1}$ are constants.

These two equations show the presence of a sinusoidal rotating MMF and therefore its interaction with a sinusoidal electromotive force provides a constant torque.

It can also be notified that the angle $\psi$ is not used in $[5,6]$. This paper takes advantage of $\psi$ to introduce a flux weakening control strategy (indeed $\mathrm{I}_{\mathrm{d} 1} \neq 0$ if $\psi \neq 0$ ). In faulted modes where the phases are disconnected, the aim of the proposed control strategy is to keep the MMF sinusoidal in order to provide a constant torque.

\section{A. MTPA control strategy with one phase disconnected}

If the phase "a" is disconnected, the current in phase "a" is nullified. In this case, it is necessary to modify the currents (the new currents are $\left.i^{\prime}{ }_{b}, i^{\prime}{ }_{c}, i^{\prime}{ }_{d}, i^{\prime}{ }_{e}\right)$ of the other phases in order to satisfy the constraint on the MMF value (to obtain a constant torque). In this case, using similar developments as in $[5,6]$ the equations become:

$$
\left\{\begin{array}{l}
\frac{5}{2} I_{\text {max }} \cos (\omega t+\psi)=\cos \left(\frac{2 \pi}{5}\right)\left(i_{b}^{\prime}+i_{e}^{\prime}\right)+\cos \left(\frac{4 \pi}{5}\right)\left(i_{c}^{\prime}+i_{d}^{\prime}\right) \\
\frac{5}{2} I_{\max } \sin (\omega t+\psi)=\sin \left(\frac{2 \pi}{5}\right)\left(i_{b}^{\prime}-i_{e}^{\prime}\right)+\sin \left(\frac{4 \pi}{5}\right)\left(i_{c}^{\prime}-i_{d}^{\prime}\right)
\end{array}\right.
$$

The new currents values must also respect equation (16) in the case of a wye connected machine associated with a 5-leg IGBT converter as in Figure 5.

$$
i_{b}^{\prime}+i_{c}^{\prime}+i_{d}^{\prime}+i_{e}^{\prime}=0
$$

This therefore leads to a system of three equations with four degrees of freedom.



Fig. 5. Structure of the converter-machine set 
In order to determine a unique expression of the currents, an additional equation must be added. As in [6] [12] it is assumed that all currents have the same magnitude.

$$
\begin{aligned}
& i_{b}^{\prime}=-i_{d}^{\prime} \\
& i_{c}^{\prime}=-i_{e}^{\prime}
\end{aligned}
$$

The solution of these equations gives:

$$
\begin{aligned}
& i_{b}^{\prime}=\frac{5 I_{\max }}{4\left(\sin \left(\frac{2 \pi}{5}\right)\right)^{2}} \cos \left(\omega t-\frac{\pi}{5}+\psi\right) \\
& i_{c}^{\prime}=\frac{5 I_{\max }}{4\left(\sin \left(\frac{2 \pi}{5}\right)\right)^{2}} \cos \left(\omega t-\frac{4 \pi}{5}+\psi\right) \\
& i_{d}^{\prime}=\frac{5 I_{\max }}{4\left(\sin \left(\frac{2 \pi}{5}\right)\right)^{2}} \cos \left(\omega t+\frac{4 \pi}{5}+\psi\right) \\
& i_{e}^{\prime}=\frac{5 I_{\max }}{4\left(\sin \left(\frac{2 \pi}{5}\right)\right)^{2}} \cos \left(\omega t+\frac{\pi}{5}+\psi\right)
\end{aligned}
$$

As in healthy mode, the MTPA characteristics are determined by solving a nonlinear optimization problem. In this particular case the optimization variables are $x(1)$ and $x(2)$ which respectively correspond to the maximum amplitude of the phase current $\left(x(1)=I_{\max }\right)$ and the phase-shift angle between the current and the electromotive force of each phase $(x(2)=\psi)$.

$$
\begin{aligned}
& i_{b}^{\prime}=x(1) \cos \left(\omega t-\frac{\pi}{5}+x(2)\right) \\
& i_{c}^{\prime}=x(1) \cos \left(\omega t-\frac{4 \pi}{5}+x(2)\right) \\
& i_{d}^{\prime}=x(1) \cos \left(\omega t+\frac{4 \pi}{5}+x(2)\right) \\
& i_{e}^{\prime}=x(1) \cos \left(\omega t+\frac{\pi}{5}+x(2)\right)
\end{aligned}
$$

- The objective function to be maximized is :

$C=\frac{1}{\Omega}\left(e_{b} i_{b}^{\prime}+e_{c} i_{c}^{\prime}+e_{d} i_{d}^{\prime}+e_{e} i_{e}^{\prime}\right)$

- The constraints are:

$$
\left\{\begin{array}{l}
i_{b}^{\prime} \leq I_{\max } \\
i_{c}^{\prime} \leq I_{\max } \\
i_{d}^{\prime} \leq I_{\max } \\
i_{e}^{\prime} \leq I_{\max }
\end{array}\right.
$$

$v_{b}=\left(R_{s} i_{b}^{\prime}+L \frac{d i_{b}^{\prime}}{d t}+M_{1} \frac{d\left(i_{a}^{\prime}+i_{c}^{\prime}\right)}{d t}+M_{2} \frac{d\left(i_{d}^{\prime}+i_{e}^{\prime}\right)}{d t}+e_{b}\right) \leq V_{\max }$

$$
\begin{aligned}
& v_{c}=\left(R_{s} i_{c}^{\prime}+L \frac{d i_{c}^{\prime}}{d t}+M_{1} \frac{d\left(i_{b}^{\prime}+i_{d}^{\prime}\right)}{d t}+M_{2} \frac{d\left(i_{a}^{\prime}+i_{e}^{\prime}\right)}{d t}+e_{c}\right) \leq V_{\text {max }} \\
& v_{d}=\left(R_{s} i_{d}^{\prime}+L \frac{d i_{d}^{\prime}}{d t}+M_{1} \frac{d\left(i_{c}^{\prime}+i_{e}^{\prime}\right)}{d t}+M_{2} \frac{d\left(i_{a}^{\prime}+i_{b}^{\prime}\right)}{d t}+e_{d}\right) \leq V_{\text {max }} \\
& v_{e}=\left(R_{s} i_{e}^{\prime}+L \frac{d i_{e}^{\prime}}{d t}+M_{1} \frac{d\left(i_{a}^{\prime}+i_{d}^{\prime}\right)}{d t}+M_{2} \frac{d\left(i_{b}^{\prime}+i_{c}^{\prime}\right)}{d t}+e_{e}\right) \leq V_{\text {max }}
\end{aligned}
$$

Therefore, this optimization problem can be solved for each value of the rotational speed $(\Omega)$ as in healthy mode. Solving this problem for each value of the speed allows to determine both the torque / speed characteristics and the corresponding current references.

\section{B. MTPA control strategy with two adjacentphases disconnected}

In this case, the phase "a" and the phase "b" are disconnected $\left(i_{a}=i_{b}=0\right)$, the currents (i.e. $\left.i{ }_{c}, i^{\prime}{ }_{\text {d }}, i{ }_{e}\right)$ of the healthy phases must be modified to verify the following equations:

$$
\left\{\begin{array}{l}
\frac{5}{2} I_{\text {max }} \cos (\omega t+\psi)=\cos \left(\frac{2 \pi}{5}\right)\left(i_{e}^{\prime \prime}\right)+\cos \left(\frac{4 \pi}{5}\right)\left(i_{c}^{\prime \prime}+i_{d}^{\prime \prime}\right) \\
\frac{5}{2} I_{\text {max }} \sin (\omega t+\psi)=-\sin \left(\frac{2 \pi}{5}\right)\left(i_{e}^{\prime \prime}\right)+\sin \left(\frac{4 \pi}{5}\right)\left(i_{c}^{\prime \prime}-i_{d}^{\prime \prime}\right)
\end{array}\right.
$$

In this case, the addition of the equation (32) related to the wye connection of the windings is sufficient to obtain an unique solution for $i{ }_{c}, i{ }_{d}$ and $i{ }_{e}$ :

$$
i_{c}^{\prime \prime}+i_{d}^{\prime \prime}+i_{e}^{\prime \prime}=0
$$

This unique solution is:

$$
\begin{aligned}
& i_{c}^{\prime \prime}=\frac{5 \cos \frac{\pi}{5} I_{\max }}{2\left(\sin \left(\frac{2 \pi}{5}\right)\right)^{2}} \cos \left(\omega t-\frac{2 \pi}{5}+\psi\right) \\
& i_{d}^{\prime \prime}=\frac{5\left(\cos \frac{\pi}{5}\right)^{2} I_{\max }}{2\left(\sin \left(\frac{2 \pi}{5}\right)\right)^{2}} \cos \left(\omega t+\frac{4 \pi}{5}+\psi\right) \\
& i_{e}^{\prime \prime}=\frac{5 \cos \frac{\pi}{5} I_{\max }}{2\left(\sin \left(\frac{2 \pi}{5}\right)\right)^{2}} \cos (\omega t+\psi)
\end{aligned}
$$

As in the previous case the MTPA characteristic is determined by solving an optimization problem for each speed. As previously, the optimization variables are $x(1)$ and $x(2)$ and the new current references to determine are expressed as: 


$$
\left\{\begin{array}{l}
i_{c}^{\prime \prime}=x(1) \cos \left(\omega t-\frac{2 \pi}{5}+x(2)\right) \\
i_{d}^{\prime \prime}=2 x(1) \cos \frac{\pi}{5} \cos \left(\omega t+\frac{4 \pi}{5}+x(2)\right) \\
i_{e}^{\prime \prime}=x(1) \cos (\omega t+x(2))
\end{array}\right.
$$

The objective function is also to maximize the electromagnetic torque for each value of the speed. In a similar way, constraints related to maximal current and voltage values are taken in account.

The results presented in Figure 6 are obtained for the same maximum voltage and maximum phase current for the generator and converter whose characteristics are summarized in Table I. Firstly the low speed maximum torque in faulted modes is strongly lower than in healthy mode (the considered healthy mode corresponds to sinusoidal current supply as in figure 4). This torque decrease from 37 N.m to 27 N.m for one phase opened and less than 10 N.m when two adjacent phases are opened (this last case corresponds to the most critical fault among all the case where two phases are disconnected).

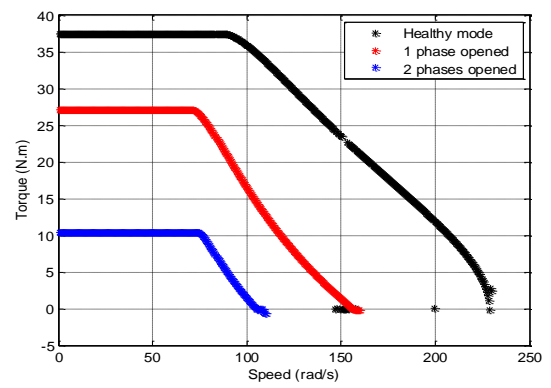

Fig. 6. MTPA Torque V.S. Speed characteristics in healthy mode and faulty modes ( 1 phase is open-circuited and 2 phases are open-circuited).

\section{CONCLUSION}

This paper presents a methodology to determine the Maximal Torque per Ampere characteristics and control strategy for a 5-phase PM generator in healthy and faulted mode ( 1 or 2 opened phases). The aim of the presented methodology is to assess the capability of a 5-phase PM Generator which can be associated with fixed-pitch tidal turbines. The proposed control strategy allows the drive being able to work in flux weakening operations in healthy mode and open-circuit mode. This kind of strategy allows controlling the fixed-pitch turbine using the MPPT with a power limitation in order to increase the efficiency of the system in the whole tidal cycle.

This work shows that a MTPA flux weakening control is possible both in healthy mode and faulty mode. The results show that a 5-phase PM generator can operate in faulty mode while maintaining relatively good performance over a high range of speed if the electrical parameters are well designed. That means that design parameters, which are directly linked to the back-EMF waveform and to the values of the inductances, influence strongly the performance of the system if this kind of control strategy is used. In fault modes, the presented work considers only generators which have a perfect sinusoidal back-EMF. The influence of the other harmonics of the backEMF on the performance of the proposed control strategy will be an interesting perspective.

\section{REFERENCES}

[1] S. Benelghali, "On Multiphysics Modeling and Control of Marine Current Turbine Systems," PhD, University of Brest, 2009.

[2] B. Multon, Marine Renewable Energy Handbook, 2011.

[3] Z. Zhou, F. Scuiller, J.-F. Charpentier, and T. Tang, "Power Limitation Control for a PMSG-Based Marine Current Turbine at High Tidal Speed and Strong Sea State," in proceedings of the 2013 IEEE on Electric Machines \& Drives Conference (IEMDC), Chicago(USA), pp. 75-80, May 2013.

[4] X. Kestelyn, E. Semail, and Y. Crevits, "Generation Of On-line Optimal Currents References for Multi-phase Permanent Magnet Machines with Open Circuited Phases," in proceedings of the 2009 IEEE on Electric Machines and Drives Conference, Miami(USA), pp. 689-694, May 2009.

[5] J.-R. Fu and T. A. Lipo, "Disturbance-free operation of a multiphase current-regulated motor drive with an opened phase," in proceedings of the 1994 IEEE Transactions on Industry Applications, vol. 30, no. 5 , September/October 1994.

[6] H. A. Toliyat, "Analysis and Simulation of Five-Phase Variable-Speed Induction Motor Drives Under Asymmetrical Connections," in proceedings of the 1998 IEEE Transactions on Power Electronics, vol. 13, no.4, pp.748-756, July 1998.

[7] N.-k. Nguyen, E. Semail, F. Meinguet, P. Sandulescu, X. Kestelyn, and B. Aslan, "Different Virtual Stator Winding Configurations of Open-End Winding Five-Phase PM Machines for Wide Speed Range Without Flux Weakning Operation," in proceedings of the 2013 IEEE on Power Electronics and Applications (EPE), Lille(France), pp. 1-8, September 2013.

[8] E. Semail, F. Meibody-Tabar, M.-F. Benkhoris, H. Razik, M. Pietrzak-David, E. Monmasson, A. Bouscayrol, B. Davat, P. Delarue, B. De Fornel, J.-P. Hautier, J.-P. Louis, and S. Pierfederici, "Représentations SMM de Machines Polyphasées," European Journal of Electrical Engineering (EJEE), vol. 8, no. 2, pp. 221-239, 2005.

[9] S. Benelghali, F. Mekri, M. Benbouzid, and J.-F. Charpentier, "Performance comparison of three — and five-phase permanent magnet generators for marine current turbine applications under opencircuit faults " in proceedings of the 2011 IEEE on Power Engineering, Energy and Electrical Drives (POWERENG), Malaga(Spain), pp. 1-6, May 2011.

[10] X. Kestelyn, "Modélisation vectorielle multimachines pour la commande des ensembles convertisseurs-machines polyphasés," PhD, University of Lille1, 2003.

[11] L. Lu, B. Aslan, L. Kobylansky, P. Sandulescu, F. Meinguet, X. Kestelyn, and E. Semail, "Computation of optimal current references for flux-weakning of multi-phase synchronous machines," in proceedings of the 2012 IEEE on IECON Montreal(Canada), pp. 3610-3615, October 2012.

[12] A. Mohammadpour and L. Parsa, "A Unified Fault-Tolerant Current Control Approach for Five-Phase PM Motors with Trapezoidal Back EMF under Different Stator Winding Connections," in proceedings of the 2013 IEEE Transactions on Power Electronics, vol. 28, no. 7, pp. $3517-3527$, July 2013 